\section{A five-year review of cases appearing before the General Dental Council's Professional Conduct Committee}

\author{
P. Singh, ${ }^{1}$ E. Mizrahi ${ }^{2}$ and S. Korb ${ }^{3}$
}

VERIFIABLE CPD PAPER
IN BRIEF

- Cases are reviewed and presented with the types of charges brought against registrants.

- Changes to the conduct procedures are outlined.

- There has been a year on year increase in the number of cases heard.

- The review should stimulate greater levels of diligence for all the dental team.

The General Dental Council (GDC) has as its primary responsibility the protection of the general public by regulating all dental professionals in the United Kingdom. Complaints brought to the attention of the GDC regarding the conduct of members of the dental profession are dealt with in a regulated manner.

This study briefly reviews the relevant procedures and analyses 209 cases brought before the Professional Conduct Committee of the GDC over a five-year period.

The results show an annual increase from 23 cases in 2003 to 65 cases in 2007 (0.18\% of registered dentists) and provide information on the geographic distribution of registrants as well as their country of origin and year of qualification. The charges, outcomes and determinations give an indication of the clinical and non-clinical misdemeanours committed by members of the profession. The outcomes and final determinations handed down (56 erasures and 37 suspensions) reflect the serious view the GDC holds regarding the professional conduct of all dental professionals.

\section{INTRODUCTION}

The General Dental Council (GDC) is a body established in 1956 by statute with regulatory powers assigned by statute. ${ }^{1}$ The main purpose of the GDC is to protect the public by regulating dental professionals in the United Kingdom. This function is highlighted in its mission statement which appears on the GDC website. ${ }^{2}$ Hew Mathewson, the current GDC president stated that 'regulators such as the GDC should owe no one any favours' and that its members should be there not to represent those who elected them but regulate dentists to protect their patients. ${ }^{3}$

A harmonious inter-relationship between the dental profession and the GDC is an essential prerequisite for the

\footnotetext{
1*Orthodontic Department, Ipswich Hospital and The Royal London Hospital, New Road, Whitechapel, London, E1 1BB; ${ }^{2}$ FTTA in Orthodontics, Whipps Cross University Hospital, London, E11 1NR; ${ }^{3}$ General Dental Practitioner, Liverpool, L25 3SZ

*Correspondence to: Dr Parmjit Singh

Email: parmjitsingh@ @otmail.com
}

\section{Refereed Paper}

Accepted 19 December 2008

DOI: 10.1038/sj.bdj.2009.121

${ }^{\circledR}$ British Dental Journal 2009; 206: 217-223 provision of high quality dental services throughout the United Kingdom. All 35,408 (31 December 2007) registered members of the profession are required to practise in accordance with the guidance document Standards for dental professionals which came into effect on the 1 June 2005. ${ }^{4}$

While the practice of dentistry continues to change, develop and evolve in tune with both technological advances and the perceptions and requirements of patients, the GDC as a regulatory body has also found it necessary to institute changes to its structure and function. There have been a number of amendments to the Dentist's Act of 1984, through Section 60 Orders of the Health Act of 1999. ${ }^{5}$ This has resulted in modernisation of legislation to enable regulatory bodies including the GDC to act quickly and effectively when a complaint is received.

The GDC has committed itself to working towards the Department of Health's vision for more effective regulation as set out in a recent Government White Paper 'Trust, Assurance and Safety'. ${ }^{6}$ The aim of reform for all the regulatory bodies of the healthcare professions is that they should be streamlined, with much greater patient and public involvement.

A complaint referred to the GDC against any dental professional has a major impact on the individual and the potential for devastating social and financial consequences.

The aim of this study is to provide a brief review of the functioning mechanism of the GDC and to evaluate all the cases that have been referred to the Professional Conduct Committee (PCC) of the GDC over a five-year period extending from January 2003 to December 2007. The information provided by such a review may enlighten, stimulate or initiate greater levels of diligence for all.

\section{What the GDC expects of its professionals}

The GDC sets high standards of dental practice and professional behaviour. Previously such guidance was made available to dentists in a document entitled Maintaining Standards ${ }^{7}$ first issued in 1997 and prior to that Fitness to Practise $^{8}$ issued in 1993. The new and current guidance is entitled Standards for Dental Professionals ${ }^{4}$ and sets out the standards the GDC expects of its professionals. 
The old style guidance contained within Maintaining Standards was extremely detailed and listed information on what actions might lead to a charge of serious professional misconduct. Central to the function of the GDC is the protection of the public and should a member of the public institute a complaint against a dental professional a standard procedure is initiated.

\section{Changes to conduct procedures}

In 2006, a number of key changes were introduced to the GDC complaints procedure to improve patient protection. ${ }^{5} \mathrm{New}$ rules came into force on 1 August 2006 which give different powers and rules to the GDC and its Practice Committees. There is now a transitional period where both old and new procedures are operating. This means that all complaints received after 31 July 2006 are being heard under the new rules, however, complaints received before this date will have the old rules applied. Within the next 18 months, most of the cases using the old rules will have been heard and virtually all cases will be using the new rules.

\section{Impairment of fitness to practise}

Regrettably the Act $^{1}$ did not provide an exact definition of what is and what constitutes serious professional misconduct and it is left up to the PCC itself to decide. The case which formed the basis for the model of what actually constitutes serious professional misconduct was that of Doughty $v$ General Dental Council $^{9}$ in which Lord McKay defined it along the lines of:

'...what is now required is that the General Dental Council should establish conduct connected with the profession in which the dentist concerned has fallen short, by omission or commission, of the standards of conduct expected among dentists and that such failing short as is established should be serious.'

The new procedures enable the GDC to look at potential fitness to practise issues holistically, ensuring the registrant's fitness to practise is assessed and dealt with in the right way. This approach is reinforced with a move away from the 'charge' of serious professional misconduct to consideration on whether a registrant's fitness to practise is impaired - either for reasons of health, performance or conduct. ${ }^{10}$

Broadly speaking there are three stages following a complaint to the GDC under the new regulations. ${ }^{11}$

\section{Stages of the complaints procedure}

\section{Stage 1}

A caseworker examines the allegations and provided issues are raised that the GDC can deal with, the matter is referred to the Investigating Committee (IC).

\section{Stage 2}

The Investigating Committee considers the allegation and might decide on:

1. No further action required

2. Issuing a letter of advice or warning

3. Referring the matter to the Professional Conduct Committee (PCC), Professional Performance Committee (PPC) or Health Committee which hold a public inquiry into the matter.

If the Investigating Committee decides there should be an inquiry they can refer the dental professional to the Interim Orders Committee to consider whether to impose conditions or an interim suspension until the inquiry has been held.

\section{Stage 3}

The Professional Conduct Committee (PCC) deals with cases which raise conduct issues and under the old rules follows procedures as per any British Court including rules of evidence and sworn statements from witnesses. The standard of proof under the old rules is the same as in criminal proceeding. The level of proof required has been reduced to that of a Civil Court in the new rules and regulations ie on the balance of probability rather than beyond reasonable doubt as required in Criminal Courts.

If the Professional Conduct Committee finds the dental professional's fitness to practise to be impaired, it can: ${ }^{11}$

- Erase them (for up to five years)

- Suspend them (for up to 12 months)

- Impose conditions on their registration

- Issue a reprimand

- Refer to another Practice Committee.
The Professional Performance Committee looks at cases where a registrant's poor performance is consistently falling below an acceptable standard.

The Health Committee deals with cases where registrant's fitness to practise is impaired because of a health problem; they may suspend registrants for up to 12 months or impose conditions for up to 36 months.

The Dentists Act 1984 (Section 29) provides the facility for a dentist to appeal a decision of the PCC to the High Court. ${ }^{1}$

\section{MATERIALS AND METHODS}

The GDC Press Office provided the data on all 209 cases that came before the Professional Conduct Committee of the GDC from January 2003 to December 2007. It should be noted that all the information provided is available in the public domain. Each case was scrutinised by one investigator and the data recorded in several categories. Cases related to the restoration of registrants back on to the GDC register were excluded from the study.

\section{Date of initial hearing}

The dates of the initial hearings were divided into five groups corresponding to each year of the survey and the number of hearings was recorded for each year. In order to establish the percentage of the dental population that were referred to the PCC per year, the number of dentists on the register as at December of each year, were also recorded.

\section{Registrants' addresses}

These were based on the address listed in the GDC's proceedings. This category was divided into five groups; England was divided into Northern and Southern regions by using a line drawn from the North of Bristol to the Wash, and the remaining three groups were made up of Scotland, Wales and abroad (for cases where the individual had relocated). No registrants were living in Northern Ireland at the time of the hearing.

\section{Qualification}

Registrants were divided into eight groups according to their basic and advanced qualifications. LDS, BDS, 


\begin{tabular}{|c|c|}
\hline Charge & Examples \\
\hline Poor clinical treatment & $\begin{array}{l}\text { Failure to monitor and treat periodontal disease } \\
\text { Failure to take a radiograph prior to crown preparation } \\
\text { Inappropriate use of glass ionomer cement }\end{array}$ \\
\hline Clinical records & $\begin{array}{l}\text { Failure to record periodontal charting } \\
\text { Failure to record the quantity of local anaesthetic administered } \\
\text { Keeping of records for only two years before destroying them }\end{array}$ \\
\hline Radiation & $\begin{array}{l}\text { Allowed radiographs to be taken before a patient was seen } \\
\text { Failure to report on radiographs } \\
\text { Taking of poor quality non-diagnostic radiographs }\end{array}$ \\
\hline NHS fraud & $\begin{array}{l}\text { Multiple claims to the Dental Practice Board for the same item } \\
\text { Claimed for fictitious patients } \\
\text { Misuse of modernisation funds }\end{array}$ \\
\hline Patient consent & $\begin{array}{l}\text { Did not provide a written treatment plan } \\
\text { Failure to explain risks of treatment } \\
\text { Failure to explain alternative treatment options }\end{array}$ \\
\hline Dishonesty & $\begin{array}{l}\text { Alteration of dental record } \\
\text { Fabrication of invoices } \\
\text { False claims on a curriculum vitae }\end{array}$ \\
\hline Medical and/or dental history & $\begin{array}{l}\text { Failure to take a medical history } \\
\text { Provided treatment against the advice of the patient's doctor } \\
\text { Prescribing penicillin when the patient was known to be allergic }\end{array}$ \\
\hline Requests for information & $\begin{array}{l}\text { Not making clear what treatment was available on the NHS } \\
\text { Stating the patient would not find an NHS dentist } \\
\text { Claimed that NHS remuneration for root canal was inadequate }\end{array}$ \\
\hline Mixing of NHS and private & $\begin{array}{l}\text { Failure to comply with requests from the Practice Board } \\
\text { Failure to respond to solicitor letters } \\
\text { Delay in sending records requested by the Practice Board }\end{array}$ \\
\hline Valid professional indemnity & Failure to have valid professional indemnity \\
\hline Sedation & $\begin{array}{l}\text { Being abusive to a nurse } \\
\text { Intercepting communication between an associate and the PCT } \\
\text { Failing to adequately supervise an assistant }\end{array}$ \\
\hline Management of staff & $\begin{array}{l}\text { Allowed a patient to be discharged in an unfit condition } \\
\text { Failure to provide post-sedation instructions } \\
\text { Carrying out sedation without a trained second person }\end{array}$ \\
\hline Health and safety & $\begin{array}{l}\text { Failure to sterilise dental burs } \\
\text { Having out of date emergency drugs } \\
\text { Placement of clinical waste with domestic waste }\end{array}$ \\
\hline Drug prescriptions & $\begin{array}{l}\text { Signing of blank prescription forms } \\
\text { Prescribing for staff members } \\
\text { Self prescribing }\end{array}$ \\
\hline Fraud outside dentistry & $\begin{array}{l}\text { Obtaining money by deception } \\
\text { False accounting } \\
\text { Obtaining property by deception }\end{array}$ \\
\hline Patient accounts & $\begin{array}{l}\text { Charged for treatment that was not provided } \\
\text { Failure to pay laboratory bill } \\
\text { Offering free treatment but then requesting payment }\end{array}$ \\
\hline Complaints & $\begin{array}{l}\text { Failure to respond to complaints } \\
\text { Delaying a response to a complaint } \\
\text { Poor handling of a complaint }\end{array}$ \\
\hline Sexually related & $\begin{array}{l}\text { Viewing of pornographic material on a Trust computer } \\
\text { Having sex with a minor } \\
\text { Sexual assault }\end{array}$ \\
\hline Back up or replacement service & $\begin{array}{l}\text { Being absent from the surgery without arranging cover } \\
\text { Leaving a practice without three months' notice to the PCT } \\
\text { Moving from one practice to another without sufficient notice }\end{array}$ \\
\hline \multicolumn{2}{|l|}{ Unknown } \\
\hline Drink or drugs & $\begin{array}{l}\text { Working drunk } \\
\text { Being in possession of illegal drugs } \\
\text { Drink driving }\end{array}$ \\
\hline General anaesthesia & Providing general anaesthesia in an inappropriate setting \\
\hline
\end{tabular}

advanced (any further postgraduate qualification), dual qualifications (medical and dental) and a group for registrants who had foreign degrees and had completed the statutory examination as required by the GDC. In view of the lack of clarity regarding the degrees of some registrants qualified abroad, it was necessary to establish a group labelled 'unknown'. Hygienists and therapists were placed into their own groups.

\section{Place of qualification}

Each registrant was grouped according to the country where the initial qualification was obtained.

\section{Year of qualification}

The data were divided into five groups: pre-1967, 1968-1977, 1978-1987, 19881997 and 1998-2007. Data for two cases were not available; these were placed in a group labelled 'unknown'.

\section{Charges}

All the charges listed for each registrant were scrutinised and categorised in groups we believe best described the charge. The groups devised along with examples of the charges are shown in Table 1. Most registrants faced charges on more than one issue with only a few single issue cases. Single issue charges usually related to preceding criminal convictions.

\section{Outcomes}

Based on the terminology used by the GDC, the outcomes were categorised into the following groups:

- guilty of serious professional misconduct (old rules)

- guilty of misconduct; related to hygienists and therapists (old rules)

- found not guilty of serious professional misconduct (old rules)

- fitness to practise found to be impaired by conduct (new rules)

- fitness to practise found to be impaired by conviction (new rules)

- fitness to practise found to be impaired by health (new rules)

- fitness to practise found to be not impaired (new rules)

- case adjourned

- unknown. 
In cases where registrants had previous criminal convictions, for some of these, the GDC considered the conviction appropriate and no further action was recommended with the case being concluded, while for other cases, the GDC considered it necessary to impose a determination of its own in addition to the external conviction.

\section{Determination}

As above, based on the terminology used by the GDC, the sanctions imposed on registrants were categorised into the following groups:

- Erased with immediate suspension

- Erased

- Suspended

- Conditions to registration applied

- Admonished/reprimanded

- Disapproval expressed

- Judgement postponed

- Case concluded

- Case adjourned

- Advice given

- Unknown.

A pilot sample of ten cases were analysed to ensure sufficient relevant data was being collected. For cases with incomplete data, the GDC were again contacted in order to obtain further information. Data were computerised using a software programme for descriptive statistical analysis (Statistical Package for the Social Sciences programmes. Version 13.0. Chicago, Il 60606 USA).

\section{RESULTS}

\section{Date of initial hearing}

The results presented in Figure 1 show a year on year increase in the number of cases heard by the PCC. Since restoration cases were excluded from the study, the figure underestimates the actual work of the PCC. There was little difference in the numbers between the years 2003 (23, 11\%) and $2004(25,12 \%)$ however, the numbers rise markedly in 2005 (37, 17.7\%) and again in 2006 (58, 27.8\%), from 2006 to 2007 the increase is less marked $(66,31.5 \%)$. The number of dentists on the register at the end of each year is shown in Table 2 along with the percentage of these dentists brought

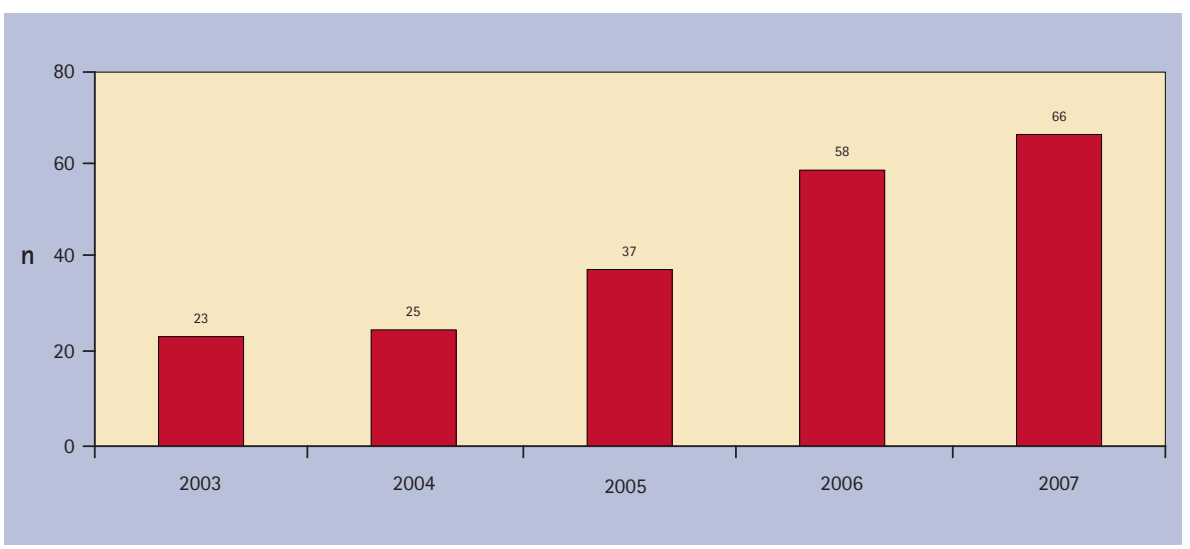

Fig. 1 Number of hearings each year for the five year period $(n=209)$

Table 2 The number of dentists on the register at the end of each year and the percentage of these who were heard at the GDC. Figures for hygienists and therapists are shown in brackets

\begin{tabular}{|l|l|l|l|l|l|}
\hline Year & 2003 & 2004 & 2005 & 2006 & 2007 \\
\hline Dentists registered & 32,517 & 31,813 & 33,698 & 34,656 & 35,408 \\
\hline Cases heard & 23 & $24(1)$ & $34(3)$ & 58 & $65(1)$ \\
\hline$\%$ of dentists registered heard & 0.07 & 0.08 & 0.10 & 0.17 & 0.18 \\
\hline
\end{tabular}

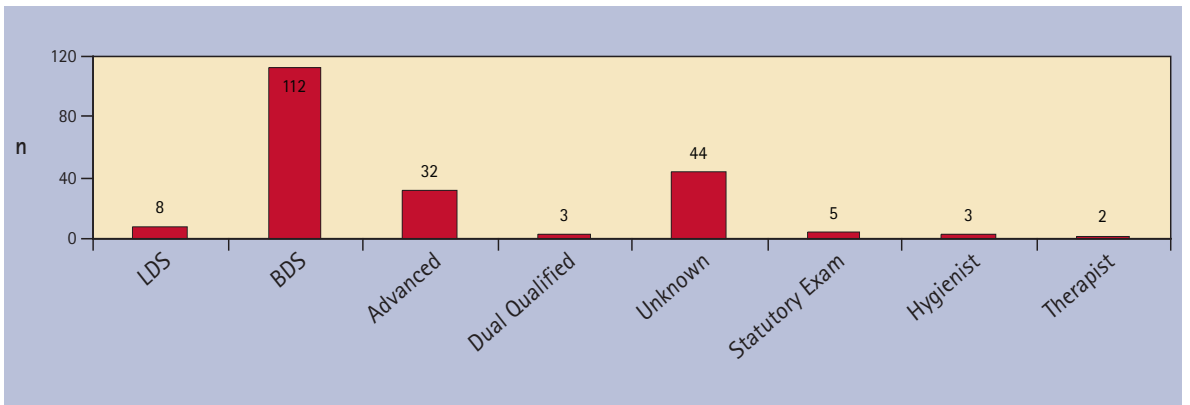

Fig. 2 Most advanced qualification of registrant $(n=209)$

before the PCC each year. The figures given in brackets refer to hygienists or therapists that came before the GDC in that year.

\section{Registrants' addresses}

The majority of registrants, $(122,58.3 \%)$ were resident in the Southern region of England (as defined above) and the bulk of the balance $(58,27.8 \%)$ were resident in the Northern region, the remaining 29, (13.9\%) were resident in Scotland, Wales and abroad.

\section{Qualification}

Figure 2 indicates that the majority of registrants (112, 53.6\%) held a BDS qualification. The second largest group referred to as 'unknown' $(44,21.1 \%)$ had degrees different to those generally recognised in the UK. Thirty-two registrants with advanced degrees comprised $15.3 \%$ of the sample.

\section{Place of qualification}

Just over half of the registrants (123, $58.9 \%$ ) graduated in the UK and the rest graduated in a distribution of 15 countries (Table 3).

\section{Year of qualification}

The majority of registrants ie 129 (61.7\%) qualified between 1978 and 1997 and $39(18.7 \%)$ qualified between 1968 and 1977. The youngest group of 26 (12.4\%) registrants qualified between 1998 and 2007 (Fig. 3). These data provide an indication of the number of years since qualification.

\section{Charges}

The frequency of the various categories of charges in descending order is listed in Table 4. Most registrants faced charges on more than one issue with only a few single issue cases which usually related to convictions. Since most registrants 


\begin{tabular}{|c|c|c|c|}
\hline & $\begin{array}{l}\text { Number of charged } \\
\text { individuals over } \\
5 \text { years }\end{array}$ & $\begin{array}{l}\text { Charged individuals } \\
\text { as a } \% \text { of the group }\end{array}$ & $\begin{array}{l}\text { Total number } \\
\text { registered at } \\
\text { Dec } 2007\end{array}$ \\
\hline United Kingdom & $122(1)$ & $58.3(0.5)$ & 29,752 \\
\hline South Africa & 23 & 11.0 & 1540 \\
\hline Sweden & 19 & 9.1 & 957 \\
\hline Germany & 8 & 3.8 & 423 \\
\hline Unknown & $4(4)$ & $1.9(1.9)$ & - \\
\hline Denmark & 4 & 1.9 & 135 \\
\hline Ireland & 4 & 1.9 & 923 \\
\hline Italy & 4 & 1.9 & 107 \\
\hline New Zealand & 4 & 1.9 & 182 \\
\hline Australia & 3 & 1.4 & 297 \\
\hline Belgium & 2 & 1.0 & 47 \\
\hline France & 2 & 1.0 & 72 \\
\hline Poland & 2 & 1.0 & 804 \\
\hline Holland & 1 & 0.5 & 0 \\
\hline Hungary & 1 & 0.5 & 130 \\
\hline Norway & 1 & 0.5 & 39 \\
\hline Total & 209 & 100 & 35,408 \\
\hline
\end{tabular}

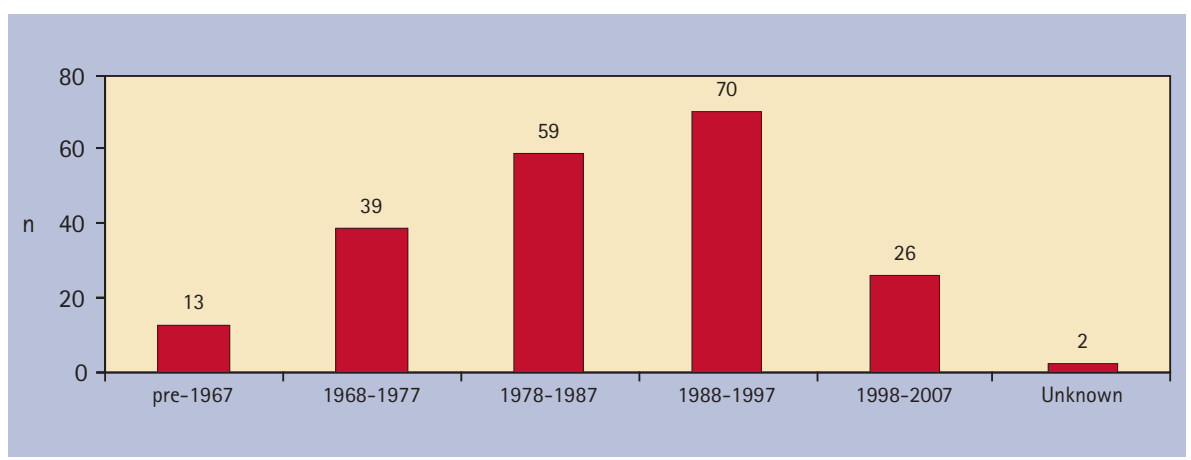

Fig. 3 Year of obtaining primary qualification $(n=209)$

incurred multiple charges, the total number of charges exceeds the number of charged registrants.

\section{Outcome}

The outcomes for the group are listed in Table 5; serious professional misconduct (147 cases $70.3 \%$ ) was the most frequent finding.

\section{Determination}

The frequencies of determinations ie the sanctions imposed by the GDC are listed in descending order in Table 6. It was possible to conclude from the determinations that of the 209 cases, 188 were heard under the old regulations, 12 were heard under the new regulations and the remaining nine were either adjourned or unknown.

\section{DISCUSSION}

Clearly there has been an increase year on year in the number of cases appearing before the PCC. It reasonable to assume this increase is due to a combination of many factors. The GDC's more robust approach as alluded to in the introduction, undoubtedly, has played a contributing role. An increase in patient awareness, expectations, demands and a general increase in the litigious nature of society has probably played the greatest role, this assumption is supported by a marked increase in the number of queries and reports received by the GDC from about 1,700 in 2003 to 3,196 in 2006. ${ }^{12}$ As further evidence, the recently established Dental Complaints Service recorded more than 16,800 phone calls during 2007. ${ }^{13}$ The annual increase in

\section{Table 4 Frequency of charges}

Charge n

Poor clinical treatment

83

Clinical records

Radiation

NHS fraud

Patient consent

Dishonesty

Medical and/or dental history

Requests for information

Mixing of NHS and private

Valid professional indemnity

Sedation

Management of staff

Health and safety

Drug prescriptions

Fraud outside dentistry

Patient accounts

Complaints

Sexually related

Back up or replacement service

Unknown

Drink or drugs

General anaesthesia

Table 5 Outcomes for the hearings ( $n=209)$

\begin{tabular}{|l|l|}
\hline Outcome & $\mathrm{n}$ \\
\hline Guilty of serious professional misconduct & 147 \\
\hline $\begin{array}{l}\text { Not guilty of serious professional } \\
\text { misconduct }\end{array}$ & 37 \\
\hline Case adjourned & 8 \\
\hline Fitness to practise impaired by conduct & 7 \\
\hline Guilty of misconduct & 4 \\
\hline Fitness to practise impaired by conviction & 2 \\
\hline Fitness to practise impaired by health & 2 \\
\hline Fitness to practise not impaired & 1 \\
\hline Unknown & 1 \\
\hline
\end{tabular}

\begin{tabular}{l|l}
\hline \multicolumn{2}{l}{ Table 6 Determinations for the hearings } \\
( $n=209)$ & $n$ \\
\hline Determination & 42 \\
\hline Admonished/reprimanded & 37 \\
\hline Case concluded & 37 \\
\hline Erased with immediate suspension & 37 \\
\hline Suspended & 19 \\
\hline Erased & 14 \\
\hline Disapproval expressed & 10 \\
\hline Case adjourned & 7 \\
\hline Judgement postponed & 3 \\
\hline Conditions applied & 2 \\
\hline Advice given & 1 \\
\hline Unknown &
\end{tabular}


the number of practising dentists may well be a further contributing factor.

While the number of dentists on the register has increased from 32,517 in 2003 to 35,408 in 2007 the number of cases as a percentage of the dental population, unfortunately, has not remained level, but has increased from $0.07 \%$ in 2003 to $0.18 \%$ in 2007 . While every case that comes before the PCC is regrettable, some consolation may be derived from the fact that the percentage in relation to the dental population is small.

The address of registrants probably reflects the population spread of dental professionals in the UK. However, whether regional variations in socioeconomic factors influence the standard of practice or possibly the dental expectations of the patient population is interesting but speculative and falls outside the scope of this article.

As expected, most registrants held a BDS qualification (Fig. 2) however, it is interesting to note that $44(21.1 \%)$ registrants held foreign degrees that were not readily recognised in terms of UK degrees. This relates well with the $23.8 \%$ of dentists with foreign degrees practising in the UK as at December 2006. ${ }^{12}$ Although not directly comparable, statistics for the NHS workforce show that as at the 31 March 2006, of the 21,111 NHS dentists 21\% qualified outside the UK. ${ }^{14}$ During 2004, 199 foreign dentists passed the International Qualifying Examination (IQE); this increased to 272 dentists in 2006. According to the GDC, this continuing increase was still not matching the demand for examination places. ${ }^{12}$ While an increasing number of foreign dentists take the Statutory Examinations each year, there are 4,504 registered foreign dentists from the European Economic Area (EEA) who are not required to sit the statutory examination. ${ }^{12}$

Evaluation of the information regarding the country of origin shows that for this sample of registrants who appeared before the PCC, 58.9\% graduated in the UK followed by South African and Swedish graduates who comprised 11\% and $9.1 \%$ of registrants respectively (Table 3). These data need to be viewed in the context of the number of dentists from different countries registered with the GDC (Table 3). The number of charged individuals is spread over five years while the totals for registered dentists are given for the end of December 2007 thus it is not possible to give an accurate percentage of charged individuals related to the total registered dentists for each country. Evaluation of NHS statistics shows that at 31 March 2006 of the 21,111 dentists registered with the NHS, the country of origin for the three largest groups were UK 15,405 (78.7\%), South Africa 896 (4.6\%) and Sweden 747 (3.8\%). ${ }^{14}$ Furthermore, for the year ending 31 March 2006, nearly 46\% of new NHS dentists qualified outside the UK. ${ }^{14}$ Percentages were calculated based on the total number of dentists whose country of qualification was known. This is the highest proportion recorded in the last ten years. Those who qualified in Poland accounted for $17 \%$ of new entrants to the NHS. The entrance of this group only started in the year 2005. It will be interesting to see if and how these changes affect the numbers and character of the charges that come before the PCC over the next few years.

Evaluation of the data on the years of initial qualification gives an indication of the number of years since qualification (Fig. 3). From the results it would appear that the bulk of registrants graduated between 1978 and 1997 ie ten to 30 years ago. This group appears to have lost the apprehension or caution of the young graduate and may have not yet acquired the maturity of the older practitioner. It could also be argued that this group of practitioners are at their peak with regard to drive, energy and earning capacity and some individuals may at times be tempted to push the boundaries of good practice.

The charges brought against the registrants in this study (which may or may not be the same as the actual heads of charge proved) cover a wide range of issues within and outside dental practice (Table 4). Most charges are related to issues of clinical practice: poor treatment (83), poor records (61), radiation (59) and NHS fraud (57). While the first three charges are directly related to clinical practice and may be related to possible inadequacies in initial and or continuing education, the last item is not related to clinical ability or training, but directly related to financially induced dishonesty.

The outcomes as listed in Table 5, show that $147(70.3 \%)$ of registrants were found to be guilty of serious professional misconduct (old rules) with a further $11(5.3 \%)$ whose fitness to practise was impaired due to conduct, conviction or health (new rules). Thirty-seven (17.7\%) registrants were found to be not guilty of serious professional misconduct (old rules) and one $(0.5 \%)$ registrant's fitness to practise was found to be not impaired (new rules). This information would tend to support the validity of the majority of claims originally brought against these professionals while the proportion of not guilty/fitness to practise not impaired cases should remind practitioners of the presence of patients or agencies that may seek to accuse dentists of invalid charges.

The vast majority of cases were still heard under the old regulations with only 12 determinations being made using the new fitness to practise procedures. This perhaps reflects the significant time lag between the initiation of a case and its final determination. The registrant whose fitness to practise was not impaired had his/her case concluded. Of the 11 registrants found to be impaired, four were erased with immediate suspension, three had conditions applied to their practice, two were admonished and a further two were suspended. As more and more cases are heard under the new regulations, we will see increasing numbers of registrants (dentists and dental care professionals) being found to have their fitness to practise either impaired (due to conduct, conviction or health) or not impaired.

An evaluation of the determinations arrived at by the GDC (Table 6) reveals that erasures and suspensions constituted the major component of the sentences imposed. This is an indication of the serious light in which the GDC holds misdemeanours carried out by members of the profession.

\section{CONCLUSIONS}

This review has shown an annual increase in the number of dental professionals being brought before the GDC. In its mandate to protect the public, the 
GDC takes a serious view of transgressions by members of the profession and has passed sentences that in many cases remove dental professionals from the register and deprive them of a means of earning a livelihood. This must surely act as a stimulant and incentive for each member of the profession to continually strive to improve clinical standards and practise at the highest ethical level. It is reassuring to note that for the vast majority of our profession a harmonious relationship exists between dentists (and dental care professionals), patients and the GDC.
The authors are grateful to Rachel Lea, Press and Parliamentary Officer at the GDC for supplying details of all of the hearings. We are also thankful to Mike Ridler, Head of the Hearings Team at the GDC for reviewing the manuscript.

1. The Dentists Act 1984. London: Stationery Office, 1984.

2. General Dental Council. GDC - About Us - Our Mission. General Dental Council website. Available at: www.gdc-uk.org/About+us/Our+mission. Accessed 16 March 2008.

3. Mathewson H. Editorial: A profession to the core. Br Dent J 2007; 202: 365

4. Standards for dental professionals. London: General Dental Council, 2005.

5. The Health Act 1999. Section 60. London: Stationery Office, 1999

6. Department of Health. White Paper: Trust, Assurance and Safety: The Regulation of Health Professionals. London: Stationery Office, 2007.
7. Maintaining standards. London: General Dental Council, 1997.

8. Fitness to practise. London: General Dental Council, 1993.

9. Doughty v General Dental Council 1988 AC 164.

10. GDC Gazette summer 2006. London: General Dental Council 2006.

11. GDC - General Public - Reporting Unfitness to Practise - The 3 stages of our Complaints Procedure. General Dental Council website. Available at: www.gdc-uk.org/General+public/ Reporting +unfitness+to+practise/ Stages+of+complaints+procedure.htm. Accessed 16 March 2008.

12. Annual Report 2006. London: General Dental Council, 2006.

13. Dental Complaints Service. Annual Report 2007 London: General Dental Council, 2007.

14. The Information Centre. NHS Dental Activity and Workforce Report 2006. London: The Information Centre, 2006. 